\title{
Whole grain intakes in the diets of Irish children and teenagers
}

\author{
Niamh F. C. Devlin ${ }^{1}$, Breige A. McNulty ${ }^{1}$, Michael J. Gibney ${ }^{1}$, Frank Thielecke ${ }^{2}$, \\ Hayley Smith ${ }^{2}$ and Anne P. Nugent ${ }^{1 *}$ \\ ${ }^{1}$ UCD Institute of Food and Health, University College Dublin, Dublin 4, Republic of Ireland \\ ${ }^{2}$ Cereal Partners Worldwide, Lausanne, Switzerland
}

(Submitted 6 July 2012 - Final revision received 1 October 2012 - Accepted 5 October 2012 - First published online 11 December 2012)

\begin{abstract}
A growing body of evidence supports the inclusion of whole grain foods in the diet to help prevent certain chronic diseases. Although much of the research has been conducted in adult cohorts, it is thought that younger populations may also benefit from whole-grainrich diets. The aim of the present study was to quantify the intake of whole grain in Irish children and teenagers, and assess the major sources of intake. Data used in the present study were from the National Children's Food Survey and the National Teens' Food Survey, which used $7 \mathrm{~d}$ food diaries to collect data on habitual food and beverage consumption in representative samples of Irish children and teenagers. Results showed that over $90 \%$ of children (5-12 years) and over $86 \%$ of teenagers (13-17 years) are consumers of whole grain, with mean daily intakes of 18.5 and $23.2 \mathrm{~g} / \mathrm{d}$, respectively. Ready-to-eat breakfast cereals made the greatest contribution to whole grain intakes for both children and teenagers (59.3 and 44.3\%), followed by bread (14.4 and 26.5\%), with wheat being the major source of intake, accounting for over $65 \%$ of all whole grains consumed. Whole grain consumers had significantly higher intakes of fibre, $\mathrm{P}$ and $\mathrm{Mg}$ in comparison with non-consumers of whole grain, even though whole grain intakes in this sample were well below the recommendation of three servings or $48 \mathrm{~g} / \mathrm{d}$. The present study characterises, for the first time, the patterns of whole grain consumption in Irish children and teenagers and shows whole grain intake to be low.
\end{abstract}

Key words: Whole grain intakes: Children: Teenagers: Ireland: Intake patterns

The inclusion of whole-grain-rich foods in the daily diet is widely promoted, with epidemiological studies showing regular consumption of whole grain foods (three servings or $48 \mathrm{~g} / \mathrm{d}$ ) to be associated with a reduced risk of CVD, diabetes ${ }^{(1-3)}$, certain cancers $^{(4)}$ and obesity ${ }^{(5)}$. A number of randomised controled trials have also produced encouraging results, with increasing intakes favourably influencing LDL-cholesterol, systolic blood pressure, insulin and C-reactive protein ${ }^{(6-8)}$. However, much of the current research has concentrated on the adult population, with few studies considering the effects of whole grain consumption in younger age groups $^{(9,10)}$.

Whole grains have been defined by the American Association of Cereal Chemists ${ }^{(11)}$ as consisting of the intact, ground, cracked or flaked caryopsis whose principal anatomical components (the endosperm, germ and bran) are present in the same relative proportions as they exist in the intact caryopsis'. However, the definition of what qualifies as a whole grain food is widely debated, and has resulted in a variety of health and content claims. One such health claim, in relation to heart disease and certain cancers, defines whole grain foods as those containing $51 \%$ or more whole grain ingredients ${ }^{(12)}$. In comparison, to use a whole grain stamp on food packaging in Canada and the USA, the food must contain at least $8 \mathrm{~g}$ of whole grain ingredients per serving ${ }^{(13)}$. Few official government regulations define how much whole grain must be in a product to be deemed a whole grain food. As a result, studies assessing population whole grain intakes have differed in their criterion as to what qualifies as a whole grain food, with some studies including all foods containing a source of whole grain ${ }^{(14)}$, while others only include foods made with a certain amount of whole grain ${ }^{(15)}$.

Dietary recommendations for daily whole grain intakes have been proposed, with suggested intakes ranging from $48 \mathrm{~g}$ in the USA and Australia ${ }^{(16,17)}$, to $75 \mathrm{~g}$ in Sweden and Denmark ${ }^{(18)}$, to $115 \mathrm{~g}$ in the Netherlands ${ }^{(19)}$; however, the $\mathrm{UK}^{(20)}$ and Germany ${ }^{(21)}$ have a more vague approach, and suggest that 'cereal products such as bread, pasta, rice and grain should preferably be whole grain'. Despite these recommendations, present intakes of whole grain in adults remain low, with research showing daily intakes in the $\mathrm{USA}^{(22)}$ and $\mathrm{UK}^{(23)}$ to be 11 and $23 \mathrm{~g}$, respectively. Intakes of whole grain in children and teenagers are also reported to be low, with daily

Abbreviations: NCFS, National Children's Food Survey; NTFS, National Teens' Food Survey; RTEBC, ready-to-eat breakfast cereal.

* Corresponding author: A. P. Nugent, email anne.nugent@ucd.ie 
intakes of $9 \cdot 8,13$ and $26.4 \mathrm{~g}$ in the $\mathrm{USA}^{(24)}, \mathrm{UK}^{(15)}$ and Germany $^{(14)}$, respectively, and just 5 and $8 \%$ of children and teenagers are meeting recommendations in Denmark ${ }^{(18)}$ and France ${ }^{(25)}$, respectively.

To date, there is no information on patterns of whole grain consumption in the Irish population, and so the aim of the present study was to quantify the intake of whole grains in the diets of Irish children and teenagers, and to assess the major sources of intake across age groups and mealtimes using data from the National Children's Food Survey (NCFS) and the National Teens' Food Survey (NTFS).

\section{Methodology \\ National Children's Food Survey and National Teens' Food Survey}

The NCFS and the NTFS were cross-sectional surveys conducted in representative samples of Irish children and teenagers between 2003-4 and 2005-6, respectively (Irish Universities Nutrition Alliance; IUNA, http://www.iuna.net). These studies were conducted according to the guidelines laid down in the Declaration of Helsinki, and all procedures involving human subjects/patients were approved by the St James's Hospital and Federated Dublin Voluntary Hospitals Joint Research Ethics Committee (NCFS) and the University College Cork Clinical Research Ethics Committee of the Cork Teaching Hospitals (NTFS). Written informed consent was obtained from all participants and their parents as appropriate. In total, 1035 participants took part (594 children: 293 boys, 301 girls and 441 teenagers: 224 males, 217 females). The age of the children was in the range from 5 to 12 years and that of the teenagers from 13 to 17 years. The overall response rate was $66 \%$ for the NCFS and $63 \%$ for the NTFS. The samples were representative of both population groups with respect to sex, age, location and social class, as per the most recent Irish census ${ }^{(26)}$. More detailed information about the population groups can be found at http://www.iuna.net

\section{Data collection}

Food and beverage intake was determined using a $7 \mathrm{~d}$ weighed food diary for the NCFS and a $7 \mathrm{~d}$ semi-weighed food diary for the NTFS. Detailed information was recorded regarding the amount and types of all foods and beverages consumed over the seven consecutive survey days (at brand level where possible). Food and beverage intakes were assessed using WISP version 3.0 (Tinuviel Software), which uses data from the McCance and Widdowson's 'The Composition of Foods' fifth and sixth editions ${ }^{(27,28)}$, plus supplemental volumes ${ }^{(29-37)}$. Food package labelling was also used to assess food and beverage intakes where necessary. Each food and beverage was allocated an individual food code and subsequently assigned to one of sixty-eight food groups for ease of analysis, e.g. savoury snacks and ready-to-eat breakfast cereals (RTEBC).

In addition to comprehensive dietary information, detailed data on socio-economic level and lifestyle were also collected. Full study details, including quantification methods used, are described by Joyce et $a l{ }^{(38)}$.

\section{The National Food and Ingredient database}

During the NCFS and the NTFS, food packaging of the consumed foods and beverages were collected and used to record information about the products. The information gathered created the Irish National Food and Ingredient Database ${ }^{(39)}$. General information recorded included brand name, product description, portion weight, country of origin and manufacturers' details. In addition, ingredient listings and nutritional information per $100 \mathrm{~g}$ of product were recorded. Where possible, foods were recorded at brand level and allocated an individual brand ID that could be linked back to actual consumption patterns.

\section{Calculation of whole grain intakes}

The NCFS and the NTFS databases were initially searched to identify potential foods made with whole grain. From the sixty-eight original food groups, fourteen were identified as containing whole grain.

All foods within each of these fourteen food groups were then checked for the presence of whole grain and a new whole grain database was created. All foods made with whole grain ingredients were included in the present study. The grains included in the present study were grouped into one of six groups: wheat, oats, rice, maize, barley and rye (Table 1).

The amount of whole grain in each product per $100 \mathrm{~g}$ was recorded in the database. As the NCFS and the NTFS collected information at brand level where possible, values for whole grain could be ascribed at a brand-specific level. These values were obtained either from the food package labelling (Irish National Food and Ingredient Database) using quantitative ingredient declaration percentages or directly from the manufacturer. Where brand-specific data were not available, the whole grain content of a comparable product was used (if the ingredient list of a known whole grain product was identical to that of an unknown product); an average of similar products was used where such detail was lacking. A recipe database previously created from the NCFS and the NTFS

Table 1. Whole grains and the classifications considered in the present study divided into one of six whole grain groups

\begin{tabular}{lllll}
\hline Wheat & Oats & Rice & Maize & Barley \\
\hline Whole grain wheat & Rolled oats & Whole grain rice & Whole grain maize & Whole barley flakes \\
Whole wheat flakes & Whole oat flour & Brown rice & Whole grain maize & Whole rye flour \\
Whole wheat durum & Oat flakes & & Popcorn & \\
Wholemeal flour & Oatmeal & & & \\
Spelt & & & & \\
\hline
\end{tabular}


was also used where appropriate, taking water losses from cooking and processing into account. The whole grain values collected per $100 \mathrm{~g}$ of product were then used to calculate the actual amounts of whole grain consumed.

For ease of analysis, the original sixty-eight food groups were reduced to ten food groups, one of which was a whole grain food group. This whole grain food group was subsequently broken down into the following seven subgroups: (1) rice, pasta and their dishes; (2) breads and rolls; (3) RTEBC; (4) other breakfast cereals (including porridge and cooked breakfast cereals); (5) sweet biscuits, cereal bars and desserts; (6) savoury biscuits, crackers and popcorn; and (7) meat products, tofu and yoghurts.

\section{Statistical analysis}

Statistical analyses were carried out using PASW Statistics version 18.0 (SPSS, Inc.). The mean and standard deviations for whole grain consumed according to sex, age group, social class, eating location and day of the week were calculated for both the total population and consumers only. Differences within the groups were detected using independent $t$ tests or by one-way ANOVA as appropriate. Independent samples $t$ tests were also used to test for significant differences in mean daily intakes of macro- and micronutrients for consumers and non-consumers of whole grain. In addition, the percentage contribution of each whole grain food group was analysed and the type of grains consumed were identified. Tertile analysis was also carried out in relation to whole grain intakes and values were adjusted for age and sex using ANCOVA. The Bonferroni post hoc test was used to identify the significant differences between each of the groups.

Further analysis was carried out to determine the proportion of Irish children and teenagers meeting whole grain recommendations set out by the United States Department of Agriculture. The data were assessed using both the recommendation of three servings (or $48 \mathrm{~g}$ ) $/ \mathrm{d}^{(16)}$ and using recommendations accounting for differences in energy intake ${ }^{(16,40)}$. For both methods, two approaches were used to assess adherence. First, the percentage of individuals in a population who met the dietary target for whole grain for the total population was calculated and referred to as 'approach 1'. However, population goals relate to the recommended mean intake of a population and it is not necessary for all individuals to achieve this intake. Compliance was also, therefore, estimated by the method of Wearne \& Day ${ }^{(41)}$ and referred to as 'approach 2'. This approach calculated the maximum size of a subgroup of the population, known as compliers, whose mean intake equals the population dietary recommendation. To calculate the percentage of compliers meeting the recommendation, mean daily whole grain intakes of each individual were ranked in descending order from the highest to the lowest. The mean intake of the group was calculated. The individual with the lowest mean intake of whole grain was then removed and the calculation repeated. This procedure continued until the mean result of the group was $\geq 48 \mathrm{~g}$. The percentage of children and teenagers achieving the whole grain recommendation was then calculated.

\section{Results}

\section{Whole grain intake}

Tables 2 and 3 present the mean daily intakes of whole grain ( $\mathrm{g} / \mathrm{d})$ for all children and teenagers. The data are described for sex, age group, social class, eating location and day of the week, for both the total population and whole grain consumers only. Overall, $90.5 \%$ of children and $86.6 \%$ of teenagers were consumers of whole grain. Mean daily intakes were 18.5 and $23.2 \mathrm{~g} / \mathrm{d}$ for children and teenagers, respectively, in the total population, rising to $20.5 \mathrm{~g} / \mathrm{d}$ (children) and $26.9 \mathrm{~g} / \mathrm{d}$ (teenagers) in consumers only. In both age groups, males consumed significantly higher amounts of whole grain than females $(22.0 \mathrm{~g} / \mathrm{d}$ in children and $28.6 \mathrm{~g} / \mathrm{d}$ in teenagers $v$. $15.1 \mathrm{~g} / \mathrm{d}$ in children and $17.7 \mathrm{~g} / \mathrm{d}$ in teenagers). Intakes of whole grain also tended to increase with age, although this was only significant for teenagers, with values in 'consumers only' increasing from $23.1 \mathrm{~g} / \mathrm{d}(13-14$ years) to $29.9 \mathrm{~g} / \mathrm{d}$ (15-17 years). The home was the primary location for whole grain consumption $(P<0.001)$, with minimal amounts eaten at other homes (e.g. home of friends, relatives and child minders) and outside of the home (e.g. restaurants). There was no significant difference between whole grain consumption at weekends in comparison to weekdays.

\section{Sources of whole grain intake}

For both children and teenagers, wheat was the major grain contributing to whole grain intake, providing 65 and $67 \%$ of whole grain intakes, respectively. Oats were the second highest contributor (16.2 and 18.4\%, respectively), with maize, rice, barley and rye providing lesser amounts of whole grain to the diet (Fig. 1).

Mean daily whole grain intakes $(\mathrm{g} / \mathrm{d})$ and the percentage contribution (\%) of the seven whole grain food groups to total whole grain intake are presented for whole grain consumers and across tertiles of intake in Table 4. For both children and teenagers, the main food group contributor to whole grain intakes was the RTEBC group (59.3 and $44.3 \%$, respectively), followed by bread and rolls ( 14.4 and $26.5 \%$, respectively). Across the tertiles of intake, those in the highest tertile had significantly greater intakes of the food groups: 'RTEBC'; 'bread and rolls'; 'savoury biscuits, crackers and popcorn'; and 'other breakfast cereals', in comparison to those children and teenagers in the lowest tertile.

As expected, for both children and teenagers, the majority of whole grain was consumed at breakfast (62.4 and 54.0\%), with more than $75 \%$ of whole grain eaten at this meal coming from RTEBC. The next most popular time to consume whole grain foods was as a snack, followed by lunch and dinner. This was evident for both children and teenagers. For children, the most popular whole grain food consumed as a snack was 'savoury biscuits, crackers and popcorn' (48\%), while 'bread and rolls' (33\%) was the most popular choice for teenagers. 'Bread and rolls' was also the main contributor to whole grain intakes at lunch for both children (54\%) and teenagers (79\%), while the 'rice, pasta and their dishes' food group was the main contributor at dinner (37 and $74.3 \%$ for children and teenagers, respectively) (data not shown). 
Table 2. Descriptive analysis of whole grain intake $(\mathrm{g} / \mathrm{d})$ for Irish children (total population and consumers only) (Mean values, medians and standard deviations; number of children and percentages)

\begin{tabular}{|c|c|c|c|c|c|c|c|c|c|c|c|c|c|c|}
\hline & \multicolumn{14}{|c|}{ Children } \\
\hline & \multicolumn{7}{|c|}{ Total population ( $n$ 594) } & \multicolumn{7}{|c|}{ Consumers only ( $n 538 ; 90.5 \%$ ) } \\
\hline & $n$ & $\%$ & Mean & Median & SD & P97.5 & $P$ & $n$ & $\%$ & Mean & Median & SD & P97.5 & $P$ \\
\hline Total population & 594 & 100 & 18.5 & $12 \cdot 7$ & $18 \cdot 2$ & 68.5 & & 538 & 90.5 & 20.5 & $14 \cdot 7$ & $18 \cdot 0$ & 68.9 & \\
\hline Sex & & & & & & & *** & & & & & & & *** \\
\hline Male & 293 & $49 \cdot 3$ & $22 \cdot 0$ & $15 \cdot 6$ & 21.5 & $72 \cdot 7$ & & 259 & 88.4 & 24.9 & $19 \cdot 2$ & $21 \cdot 1$ & $75 \cdot 2$ & \\
\hline Female & 301 & $50 \cdot 6$ & $15 \cdot 1$ & $11 \cdot 6$ & 13.5 & $49 \cdot 3$ & & 279 & $92 \cdot 7$ & $16 \cdot 4$ & $12 \cdot 4$ & $13 \cdot 2$ & $49 \cdot 4$ & \\
\hline Age & & & & & & & NS & & & & & & & NS \\
\hline Age group 1† & 296 & $49 \cdot 8$ & $17 \cdot 5$ & $12 \cdot 7$ & $16 \cdot 3$ & 60.9 & & 267 & $90 \cdot 2$ & $19 \cdot 4$ & $14 \cdot 3$ & $16 \cdot 1$ & $62 \cdot 7$ & \\
\hline Age group $2 \dagger$ & 298 & $50 \cdot 1$ & 19.5 & $12 \cdot 7$ & $19 \cdot 8$ & 71.6 & & 271 & $90 \cdot 9$ & 21.5 & $15 \cdot 2$ & $19 \cdot 7$ & $72 \cdot 3$ & \\
\hline Social class & & & & & & & ** & & & & & & & * \\
\hline Professional/managerial & 307 & $52 \cdot 4$ & $20 \cdot 7^{\mathrm{a}}$ & $15 \cdot 6$ & $18 \cdot 5$ & 68.3 & & 285 & $92 \cdot 8$ & $22 \cdot 3^{\mathrm{a}}$ & $17 \cdot 1$ & $18 \cdot 3$ & 68.5 & \\
\hline Non-manual & 117 & 20 & $18 \cdot 6^{a, b}$ & $12 \cdot 6$ & $17 \cdot 9$ & 70.9 & & 110 & 94.0 & $19 \cdot 8^{\mathrm{a}, \mathrm{b}}$ & 13.4 & $17 \cdot 8$ & $71 \cdot 1$ & \\
\hline Skilled manual & 93 & $15 \cdot 9$ & $13 \cdot 8^{\mathrm{b}}$ & $9 \cdot 1$ & $15 \cdot 4$ & $66 \cdot 7$ & & 82 & 88.2 & $15 \cdot 6^{\mathrm{b}}$ & $12 \cdot 3$ & $15 \cdot 5$ & $68 \cdot 6$ & \\
\hline Semi-skilled + unskilled & 68 & 11.6 & $14 \cdot 8^{a, b}$ & $8 \cdot 2$ & $18 \cdot 2$ & $65 \cdot 6$ & & 53 & $77 \cdot 9$ & $19 \cdot 0^{a, b}$ & $10 \cdot 8$ & $18 \cdot 6$ & 82 & \\
\hline Eating location & & & & & & & $\star * *$ & & & & & & & *** \\
\hline Home & 594 & 100 & $17 \cdot 7^{\mathrm{a}}$ & $12 \cdot 1$ & $17 \cdot 6$ & 68.5 & & 533 & 89.7 & $19 \cdot 7^{\mathrm{a}}$ & $13 \cdot 8$ & 17.5 & 68.9 & \\
\hline Other home & 349 & 58.7 & $0.79^{b}$ & 0 & 2.6 & $6 \cdot 2$ & & 83 & $23 \cdot 8$ & $3.3^{b}$ & $2 \cdot 3$ & 4.4 & 22.5 & \\
\hline Outside home & 464 & $78 \cdot 1$ & $0.55^{\mathrm{b}}$ & 0 & $2 \cdot 4$ & $6 \cdot 1$ & & 68 & 14.7 & $3.8^{\mathrm{b}}$ & $2 \cdot 7$ & $5 \cdot 2$ & $20 \cdot 4$ & \\
\hline Day of week & & & & & & & NS & & & & & & & NS \\
\hline Weekday & 594 & 100 & $19 \cdot 3$ & 13.5 & $19 \cdot 6$ & $69 \cdot 4$ & & 522 & 87.9 & 22 & $15 \cdot 9$ & $19 \cdot 4$ & $15 \cdot 9$ & \\
\hline Weekend & 594 & 100 & $16 \cdot 7$ & 9.5 & 22 & $72 \cdot 9$ & & 407 & 68.5 & 24.5 & 18.9 & $22 \cdot 7$ & 18.9 & \\
\hline
\end{tabular}

a,b Mean values with unlike superscript letters were significantly different between mean daily intakes of whole grain (ANOVA with Bonferroni correction).

Mean values were significantly different: ${ }^{\star} P<0.05$, ${ }^{\star \star} P<0.01$, ${ }^{\star \star \star} P<0.001$, NS $(P \geq 0.05)$.

†Age group 1: 5-8 years; age group 2: $9-12$ years.

\section{Whole grain intakes and dietary recommendations}

The percentage of Irish children and teenagers meeting whole grain recommendations ${ }^{(16)}$ using both 'approach 1 ' and 'approach 2', are presented in Table 5. Using approach 1, which assesses individual compliance with the recommen- dations, over $5 \%$ of children and almost $15 \%$ of teenagers were meeting the whole grain recommendation of three servings $(48 \mathrm{~g}) / \mathrm{d}$, while those meeting recommendations based on energy intake were $7 \cdot 7 \%$ for children and $12 \%$ for teenagers. Using approach 2, which focuses on the proportion

Table 3. Descriptive analysis of whole grain intake ( $\mathrm{g} / \mathrm{d}$ ) for Irish teenagers (total population and consumers only)

(Mean values, medians and standard deviations; number of children and percentages)

\begin{tabular}{|c|c|c|c|c|c|c|c|c|c|c|c|c|c|c|}
\hline & \multicolumn{14}{|c|}{ Teenagers } \\
\hline & \multicolumn{7}{|c|}{ Total population ( $n$ 441) } & \multicolumn{7}{|c|}{ Consumers only ( $n 382 ; 86.6 \%$ ) } \\
\hline & $n$ & $\%$ & Mean & Median & SD & P97.5 & $P$ & $n$ & $\%$ & Mean & Median & SD & P97.5 & $P$ \\
\hline Total population & 441 & 100 & $23 \cdot 2$ & $13 \cdot 4$ & 29.5 & $97 \cdot 9$ & & 382 & $86 \cdot 6$ & $26 \cdot 9$ & $18 \cdot 1$ & $30 \cdot 2$ & $105 \cdot 5$ & \\
\hline Sex & & & & & & & $\star \star \star$ & & & & & & & *** \\
\hline Male & 224 & $50 \cdot 7$ & $28 \cdot 6$ & $19 \cdot 3$ & $35 \cdot 0$ & $130 \cdot 7$ & & 196 & 87.5 & $32 \cdot 7$ & $23 \cdot 6$ & $35 \cdot 6$ & $137 \cdot 1$ & \\
\hline Female & 217 & $49 \cdot 2$ & $17 \cdot 7$ & $10 \cdot 5$ & $21 \cdot 3$ & $89 \cdot 1$ & & 186 & $85 \cdot 7$ & $20 \cdot 7$ & $12 \cdot 8$ & $21 \cdot 7$ & 92.9 & \\
\hline Age & & & & & & & * & & & & & & & * \\
\hline Age group 1† & 188 & $42 \cdot 6$ & $19 \cdot 6$ & $11 \cdot 2$ & 22.9 & $87 \cdot 3$ & & 161 & $85 \cdot 6$ & $23 \cdot 1$ & $15 \cdot 6$ & $23 \cdot 2$ & $92 \cdot 1$ & \\
\hline Age group $2 \dagger$ & 253 & $57 \cdot 3$ & $25 \cdot 9$ & $14 \cdot 8$ & $33 \cdot 4$ & $122 \cdot 1$ & & 221 & $87 \cdot 4$ & $29 \cdot 9$ & $19 \cdot 1$ & 34.4 & $131 \cdot 2$ & \\
\hline Social class & & & & & & & * & & & & & & & * \\
\hline Professional/managerial & 214 & $49 \cdot 9$ & $26 \cdot 5^{\mathrm{a}}$ & $17 \cdot 8$ & $32 \cdot 4$ & 96.5 & & 192 & $89 \cdot 7$ & $29 \cdot 6^{a}$ & $20 \cdot 5$ & 32.9 & $104 \cdot 8$ & \\
\hline Non-manual & 79 & $18 \cdot 4$ & $23 \cdot 1^{a, b}$ & $9 \cdot 9$ & 31.9 & 118.5 & & 67 & $84 \cdot 8$ & $27 \cdot 3^{a, b}$ & $15 \cdot 5$ & $33 \cdot 0$ & $125 \cdot 7$ & \\
\hline Skilled manual & 85 & $19 \cdot 8$ & $20 \cdot 6^{a, b}$ & $10 \cdot 7$ & $24 \cdot 2$ & 88.9 & & 73 & 85.9 & $24 \cdot 1^{a, b}$ & $13 \cdot 4$ & 24.5 & 97.5 & \\
\hline Semi-skilled + unskilled & 51 & $11 \cdot 8$ & $11 \cdot 8^{\mathrm{b}}$ & $4 \cdot 3$ & $15 \cdot 6$ & $67 \cdot 0$ & & 40 & $78 \cdot 4$ & $15 \cdot 1^{\mathrm{b}}$ & $9 \cdot 7$ & $16 \cdot 2$ & 74.4 & \\
\hline Eating location & & & & & & & 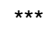 & & & & & & & *** \\
\hline Home & 441 & 100 & $21 \cdot 5^{\mathrm{a}}$ & $10 \cdot 6$ & $29 \cdot 4$ & 95.4 & & 365 & $82 \cdot 8$ & $25 \cdot 9^{a}$ & $15 \cdot 9$ & $30 \cdot 5$ & $104 \cdot 4$ & \\
\hline Other home & 192 & 43.5 & $0.9^{b}$ & 0 & $2 \cdot 8$ & $10 \cdot 3$ & & 41 & $21 \cdot 4$ & $4 \cdot 4^{\mathrm{b}}$ & $3 \cdot 1$ & $4 \cdot 6$ & $19 \cdot 2$ & \\
\hline Outside home & 421 & 95.4 & $1 \cdot 6^{\mathrm{b}}$ & 0 & 3.9 & 14.9 & & 124 & 29.5 & $5 \cdot 5^{\mathrm{b}}$ & $3 \cdot 3$ & $5 \cdot 6$ & 21.9 & \\
\hline Day of week & & & & & & & NS & & & & & & & NS \\
\hline Weekday & 441 & 100 & $24 \cdot 6$ & $14 \cdot 0$ & $32 \cdot 5$ & $117 \cdot 2$ & & 364 & 82.5 & $29 \cdot 9$ & $19 \cdot 6$ & 33.5 & $122 \cdot 9$ & \\
\hline Weekend & 441 & 100 & $20 \cdot 5$ & $7 \cdot 7$ & 31.9 & $116 \cdot 0$ & & 277 & $62 \cdot 8$ & 32.6 & $21 \cdot 8$ & $35 \cdot 0$ & 130.9 & \\
\hline
\end{tabular}

a,b Mean values with unlike superscript letters denote significant differences between mean daily intakes of whole grain (ANOVA with Bonferroni correction)

Mean values were significantly different: ${ }^{\star} P<0.05,{ }^{\star *} P<0.01,{ }^{* *} P<0.001, \mathrm{NS}(P \geq 0.05)$.

†Age group 1: 13-14 years; age group 2: 15-17 years. 
(a)

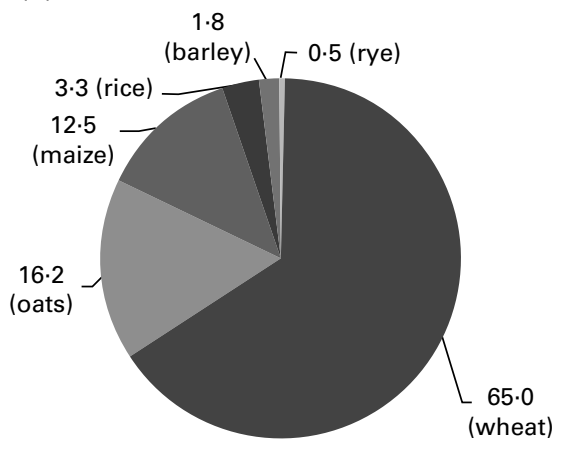

(b)

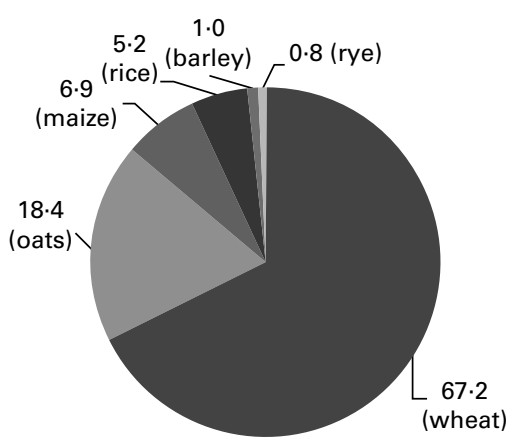

Fig. 1. Contribution of whole grain ingredients (\%) to daily whole grain intakes for Irish (a) children and (b) teenagers.

of the population that achieved the recommendations, $17 \%$ of the children and $39 \%$ of teenagers satisfied the $48 \mathrm{~g} / \mathrm{d} \mathrm{rec}-$ ommendation, while $20 \%$ of children and $32 \%$ of teenagers satisfied the recommendations based on energy intakes.

\section{Consumers v. non-consumers of whole grain}

A comparison of nutrient intakes between non-consumers and consumers of whole grain across the tertiles of intake for children and teenagers are presented in Table 6 . For both children and teenagers, significant differences were seen for mean daily intakes of energy (MJ) and for a range of nutrients (fibre, $\mathrm{P}, \mathrm{K}, \mathrm{Mg}$, riboflavin and niacin) across the tertiles of intake or when comparing consumers of whole grain with non-consumers of whole grain. The percentage energy contribution derived from added sugars for both children and teenagers was significantly lower in the highest tertile of whole grain intake in comparison to non-consumers of whole grain $(P<0 \cdot 05)$.

\section{Discussion}

The present paper analysed whole grain intakes in the diets of Irish children and teenagers. Mean daily intakes were $18.5 \mathrm{~g} / \mathrm{d}$ for children and $23.2 \mathrm{~g} / \mathrm{d}$ for teenagers, with $90 \%$ of children and $86 \%$ of teenagers being consumers of whole grain. Comparable studies around the world have found similarly low results, with mean daily intakes of $9.8,13.0$ and $26.4 \mathrm{~g} / \mathrm{d}$ in the $\mathrm{USA}^{(24)}, \mathrm{UK}^{(15)}$ and Germany ${ }^{(14)}$, respectively. Consumer rates of children and teenagers in these aforementioned studies are reported to have been 55, 73 and $80 \%$, respectively, all lower than that observed in this Irish population. However, there is currently no universally agreed list of whole grain foods and scientific studies can apply differing criteria when identifying a whole-grain-containing food, making direct comparisons between studies difficult. Moreover, a UK study only included foods made from a minimum whole grain content of $10 \%{ }^{(15)}$, in comparison to the present study and that of Alexy et al. ${ }^{(14)}$ (a German study), which included all sources of whole grain. The aim of the present study was to quantify whole grain intakes, and therefore it was deemed appropriate to include all sources of whole grain. Nevertheless, intakes were well below the dietary recommendation of $48 \mathrm{~g} / \mathrm{d}$ set out by the United States Department of Agriculture ${ }^{(16)}$, with just a maximum of $17 \%$ of children and $39 \%$ of teenagers observed to satisfy this recommendation. The suitability of applying this recommendation to younger children, where portion sizes are typically lower, is questionable; therefore, intakes were also assessed using recommendations that accounted for energy intake ${ }^{(16,40)}$. Using this second approach, similar numbers of children (20\%) and teenagers (32\%) satisfied the recommendations. Dietary recommendations for whole grain intake have been developed alongside growing evidence that increasing intakes of whole grain can protect against disease, specifically $\mathrm{CVD}^{(42)}$, type 2 diabetes ${ }^{(43)}$ and certain cancers, e.g. colorectal cancer ${ }^{(44)}$. It is likely that the mechanisms by which these benefits are likely to occur (improved inflammatory status ${ }^{(45)}$, insulin response ${ }^{(6)}$, vascular function ${ }^{(46)}$ and lipid profile ${ }^{(2)}$ ) may also play a role in younger cohorts, or at least pave the way for a healthier adulthood. Furthermore, a recent review investigating the link between whole grain consumption and colorectal cancer concluded that a diet rich in whole grains $(90 \mathrm{~g} / \mathrm{d})$ could bring about a $20 \%$ reduced risk of developing colorectal cancer. The review also highlighted the protective effects of increasing fibre intakes, particularly cereal fibre $(10 \mathrm{~g} / \mathrm{d})$, to reduce the risk by a further $10 \%{ }^{(44)}$.

The composition of whole grains (the germ, the endosperm and the outer bran layers) makes them a rich source of vitamins, minerals, fibre and antioxidants. Even within the boundaries of the present study, we found that children and teenagers who consumed whole grain had more favourable intakes of fibre and a number of micronutrients in comparison to non-consumers of whole grain. The strong association between whole grain and fibre was clearly evident in the present study, with a stepwise increase observed across the tertiles of whole grain intake. These results are comparable to an American study, which also showed a positive relationship between whole grain and fibre consumption ${ }^{(24)}$. Although previous research in the present study population has showed fibre intakes to be poor ${ }^{(47,48)}$ and below dietary recommendations ${ }^{(49)}$, the present study suggests that inclusion of whole-grain-rich foods in the daily diet presents a viable way of boosting fibre intakes as well as other micronutrients. 


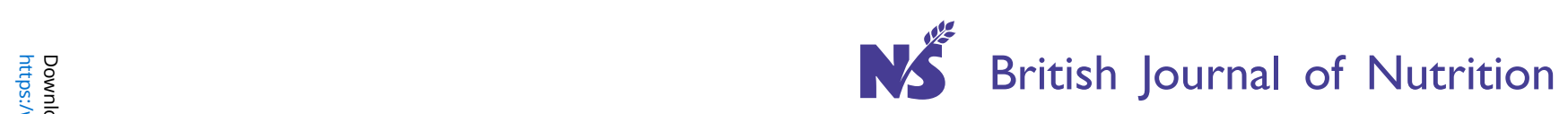

Table 4. Intake ( $/ 10 \mathrm{MJ}$ per $\mathrm{d}$ ) and contribution (\%) of food groups to mean daily whole grain intakes across tertiles of intake in whole grain consumers (Mean values and standard deviations)

\begin{tabular}{|c|c|c|c|c|c|c|c|c|c|c|c|c|c|c|c|c|c|}
\hline & \multirow{2}{*}{\multicolumn{4}{|c|}{$\begin{array}{l}\text { Whole grain consumers ( } n 538 \\
\text { children/382 teenagers) }\end{array}$}} & \multicolumn{12}{|c|}{ Tertiles of mean daily whole grain intakes ( $g / 10 \mathrm{MJ}$ per $\mathrm{d}$ ) } & \multirow[b]{3}{*}{$P$} \\
\hline & & & & & \multicolumn{4}{|c|}{$\begin{array}{c}\text { Tertile } 1 \text { ( } n 179 \text { children/127 } \\
\text { teenagers) }\end{array}$} & \multicolumn{4}{|c|}{$\begin{array}{c}\text { Tertile } 2 \text { ( } n 180 \text { children/128 } \\
\text { teenagers) }\end{array}$} & \multicolumn{4}{|c|}{$\begin{array}{c}\text { Tertile } 3 \text { ( } n 179 \text { children/127 } \\
\text { teenagers) }\end{array}$} & \\
\hline & $\%$ Cons & Mean & SD & $\% \mathrm{Ctr}$ & $\%$ Cons & Mean & SD & $\% \mathrm{Ctr}$ & $\%$ Cons & Mean & SD & $\%$ Ctr & $\%$ Cons & Mean & SD & $\% \mathrm{Ctr}$ & \\
\hline \multicolumn{18}{|c|}{ Ready-to-eat breakfast cereals } \\
\hline Children & $72 \cdot 3$ & $22 \cdot 2$ & $19 \cdot 0$ & $59 \cdot 3$ & $45 \cdot 8$ & $7.5^{\mathrm{a}}$ & 4.8 & 41.0 & $79 \cdot 4$ & $16 \cdot 1^{\mathrm{b}}$ & 8.6 & $56 \cdot 0$ & 91.6 & $35.0^{\mathrm{c}}$ & 21.9 & $62 \cdot 7$ & *** \\
\hline Teenagers & $59 \cdot 2$ & $21 \cdot 8$ & $19 \cdot 8$ & 44.3 & $29 \cdot 1$ & $5 \cdot 7^{\mathrm{a}}$ & $2 \cdot 6$ & $28 \cdot 0$ & $71 \cdot 1$ & $14 \cdot 7^{\mathrm{b}}$ & $9 \cdot 6$ & 47.5 & $77 \cdot 2$ & $34.0^{\mathrm{c}}$ & $22 \cdot 7$ & $42 \cdot 9$ & $\star \star \star *$ \\
\hline \multicolumn{18}{|l|}{ Bread and rolls } \\
\hline Children & 33.8 & $11 \cdot 8$ & $12 \cdot 8$ & 14.4 & 24.0 & $5 \cdot 0^{\mathrm{a}}$ & 3.1 & $16 \cdot 2$ & 30.6 & $8 \cdot 8^{\mathrm{b}}$ & 6.4 & 11.7 & 46.9 & $17 \cdot 2^{\mathrm{C}}$ & $16 \cdot 2$ & $15 \cdot 2$ & *** \\
\hline Teenagers & $49 \cdot 0$ & $17 \cdot 7$ & 20.5 & 26.5 & 33.1 & $5 \cdot 7^{\mathrm{a}}$ & 3.8 & $30 \cdot 4$ & $45 \cdot 3$ & $12 \cdot 4^{\mathrm{a}}$ & $8 \cdot 1$ & $21 \cdot 3$ & 68.5 & $27 \cdot 4^{\mathrm{b}}$ & $26 \cdot 3$ & 30.6 & $\star \star \star *$ \\
\hline \multicolumn{18}{|c|}{ Savoury biscuits, crackers and popcorn } \\
\hline Children & 40.9 & 8.2 & 7.8 & $12 \cdot 0$ & 31.3 & $5 \cdot 5^{a}$ & 3.5 & 21.5 & $47 \cdot 8$ & $8 \cdot 3^{\mathrm{b}}$ & $5 \cdot 7$ & $19 \cdot 3$ & 43.6 & $9 \cdot 9^{\mathrm{c}}$ & 11.0 & $8 \cdot 1$ & *** \\
\hline Teenagers & $27 \cdot 2$ & 8.5 & $6 \cdot 8$ & $7 \cdot 2$ & $22 \cdot 0$ & $4 \cdot 2^{\mathrm{a}}$ & $2 \cdot 8$ & $15 \cdot 1$ & $32 \cdot 8$ & $11 \cdot 7^{\mathrm{b}}$ & $7 \cdot 0$ & $16 \cdot 1$ & $26 \cdot 8$ & $8 \cdot 2^{\mathrm{b}}$ & $7 \cdot 0$ & 3.6 & *** \\
\hline \multicolumn{18}{|c|}{ Other breakfast cereals } \\
\hline Children & $19 \cdot 3$ & 8.8 & $10 \cdot 6$ & 6.5 & 14.0 & $3 \cdot 1^{a}$ & $2 \cdot 7$ & 5.6 & $20 \cdot 6$ & $7 \cdot 1^{\mathrm{b}}$ & 5.5 & $7 \cdot 7$ & 23.5 & $14.0^{\mathrm{C}}$ & 14.5 & $6 \cdot 2$ & $* \star *$ \\
\hline Teenagers & $17 \cdot 0$ & $18 \cdot 1$ & $18 \cdot 2$ & $10 \cdot 8$ & 8.7 & $5 \cdot 0^{\mathrm{a}}$ & 2.9 & $7 \cdot 1$ & $15 \cdot 6$ & $12 \cdot 9^{\mathrm{a}}$ & 9.0 & $9 \cdot 1$ & 26.8 & $25 \cdot 6^{\mathrm{b}}$ & 21.4 & 11.2 & *** \\
\hline \multicolumn{18}{|c|}{ Rice, pasta and their dishes } \\
\hline Children & 4.6 & 24.8 & $19 \cdot 0$ & 3.9 & NA & NA & NA & NA & $2 \cdot 8$ & $10 \cdot 4$ & $10 \cdot 0$ & 1.2 & $11 \cdot 2$ & 28.4 & $19 \cdot 2$ & 5.4 & NA \\
\hline Teenagers & 8.8 & 40.9 & 27.9 & 6.6 & 0.8 & 5.2 & NA & 1.3 & 1.6 & $7.5^{\mathrm{a}}$ & 4.4 & 0.4 & 13.4 & $46 \cdot 9^{\mathrm{b}}$ & $25 \cdot 7$ & 8.6 & * \\
\hline \multicolumn{18}{|c|}{ Sweet biscuits, cereal bars and desserts } \\
\hline Children & 33.5 & $2 \cdot 3$ & 2.4 & $2 \cdot 7$ & $30 \cdot 7$ & $2 \cdot 1$ & $2 \cdot 2$ & 8.9 & 31.7 & $2 \cdot 2$ & $2 \cdot 2$ & $3 \cdot 2$ & $38 \cdot 0$ & 2.5 & $2 \cdot 8$ & 1.9 & NS \\
\hline Teenagers & 65.0 & 2.5 & 2.8 & 3.2 & $33 \cdot 1$ & 1.9 & 1.8 & $10 \cdot 7$ & 33.6 & $2 \cdot 3$ & $2 \cdot 0$ & 3.6 & 48.8 & 3.0 & 3.7 & 2.4 & NS \\
\hline \multicolumn{18}{|c|}{ Meat, tofu and yoghurts } \\
\hline Children & 14.9 & $2 \cdot 1$ & 1.4 & $1 \cdot 1$ & 21.8 & $2 \cdot 3$ & 1.6 & 6.7 & $10 \cdot 0$ & $2 \cdot 3$ & 1.4 & 0.9 & $12 \cdot 8$ & 1.8 & 1.0 & 0.5 & NS \\
\hline Teenagers & 17.5 & $2 \cdot 3$ & 2.0 & 1.4 & $17 \cdot 3$ & 2.5 & 1.7 & 7.4 & 14.8 & 2.9 & $2 \cdot 7$ & 2.0 & 20.5 & 1.8 & 1.4 & 0.6 & NS \\
\hline
\end{tabular}

$\%$ Cons, \% consumers of each whole grain food group; \% Ctr, \% contribution of food groups to whole grain intakes; NA, not available.

a,b,c Mean values with unlike superscript letters were significantly different between the mean values of whole grain intake across the tertiles of whole grain intake (adjusted for sex) (ANCOVA, Bonferroni post hoc test). Mean values were significantly different: ${ }^{*} P<0.05 ;{ }^{* * *} P<0.001$; NS $(P \geq 0.05)$ 
Table 5. Percentage of Irish children and teenagers from the National Children's Food Survey and the National Teens' Food Survey meeting the whole grain recommendations advised by the United States Department of Agriculture ${ }^{(52)}$

\begin{tabular}{|c|c|c|c|c|}
\hline \multirow[b]{3}{*}{ Total population } & \multicolumn{4}{|c|}{ Irish children and teenagers meeting whole grain recommendations } \\
\hline & \multicolumn{2}{|c|}{ Recommendation of $48 \mathrm{~g} / \mathrm{d}$} & \multicolumn{2}{|c|}{$\begin{array}{c}\text { Recommendation based on energy } \\
\text { intakes* }\end{array}$} \\
\hline & Approach 1 & Approach 2 & Approach 1 & Approach 2 \\
\hline Children (5-12 years) & 5.5 & $17 \cdot 2$ & $7 \cdot 7$ & $20 \cdot 4$ \\
\hline Teenagers $(13-17$ years $)$ & $14 \cdot 7$ & $39 \cdot 2$ & $12 \cdot 0$ & $32 \cdot 4$ \\
\hline
\end{tabular}

The major food group contributing to whole grain intake was RTEBC (52\%). Other countries have also presented similarly high results, with RTEBC contributing 56\% to whole grain intakes in British children and teenagers ${ }^{(15)}$, while in America, this figure is $31 \%{ }^{(50)}$. The high consumption rates of whole grain RTEBC observed in this Irish population was no surprise ( $72 \%$ of children and $59 \%$ of teenagers), as earlier research has shown over $90 \%$ of Irish children and $81 \%$ of teenagers to be consumers of RTEBC ${ }^{(51,52)}$. European studies examining the change in food choices over time have also reported intakes of RTEBC to be rising ${ }^{(14,53)}$.

There are a number of strategies that could be followed to increase whole grain intakes in this population. For whole grain breakfast cereals, bread and rolls, the potential remains to increase the range of whole grain varieties available and/ or to encourage an increased frequency of consumption of existing foods. Another option involves the food groups 'savoury biscuits, crackers and popcorn' and 'sweet biscuits, cereal bars and desserts'. Typically, these foods are deemed as 'treat foods' due to their fat, salt and/or sugar content, yet both groups made small contributions to whole grain intake (12\% on average), and over 34 and $49 \%$ of the present study sample were consumers of these food groups. A practical way to increase whole grain intakes in this population is to act on the finding that whole grain foods are poorly consumed outside of the home, and to work with various stakeholders to increase the availability of whole-grain-containing foods in restaurants and catering establishments. On a positive note, the overall high rate of whole grain consumers, as seen in the present study, contests previous views that inferior taste and texture may be the reason for such poor compliance ${ }^{(54)}$. It may also reflect the 20-fold increase in availability of products made with whole grain in the last decade ${ }^{(55)}$. Such increasing availability, coupled with growing consumer

Table 6. Mean daily intakes of energy ( $\mathrm{MJ} / \mathrm{d}$ ), and macro- and micronutrients (per $10 \mathrm{MJ}$ and \% total energy) for non-consumers of whole grain and across tertiles of mean daily whole grain intakes in Irish children and teenagers

\begin{tabular}{|c|c|c|c|c|c|c|c|c|c|c|}
\hline & \multicolumn{5}{|c|}{ Children } & \multicolumn{5}{|c|}{ Teenagers } \\
\hline & \multicolumn{5}{|c|}{ Tertiles of mean daily whole grain intakes } & \multicolumn{5}{|c|}{ Tertiles of mean daily whole grain intakes } \\
\hline & $\begin{array}{l}\text { Non- } \\
\text { consumers }\end{array}$ & Tertile 1 & Tertile 2 & Tertile 3 & $P$ & $\begin{array}{l}\text { Non- } \\
\text { consumers }\end{array}$ & Tertile 1 & Tertile 2 & Tertile 3 & $P$ \\
\hline Energy (MJ) & $6 \cdot 8^{\mathrm{a}}$ & $6 \cdot 7^{\mathrm{a}}$ & $6 \cdot 9^{\mathrm{a}}$ & $7 \cdot 6^{\mathrm{b}}$ & $\star \star \star \star ~$ & $7 \cdot 6^{a}$ & $7 \cdot 8^{\mathrm{a}}$ & $8 \cdot 1^{a}$ & $9 \cdot 4^{\mathrm{b}}$ & 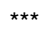 \\
\hline$\%$ Energy from protein & $13 \cdot 2$ & $13 \cdot 4$ & $13 \cdot 6$ & $13 \cdot 9$ & NS & $14 \cdot 0^{\mathrm{a}}$ & $14 \cdot 3^{a}$ & $14 \cdot 9^{a, b}$ & $15 \cdot 4^{b}$ & ** \\
\hline$\%$ Energy from carbohydrate & $53 \cdot 1$ & 51.4 & $52 \cdot 1$ & $52 \cdot 1$ & NS & 48.9 & 48.5 & $48 \cdot 8$ & $49 \cdot 8$ & NS \\
\hline$\%$ Energy from total sugar & $24 \cdot 3$ & 24.2 & $24 \cdot 0$ & 23.4 & NS & 20.5 & $20 \cdot 1$ & $20 \cdot 4$ & 20.7 & NS \\
\hline$\%$ Energy from added sugar & $16 \cdot 4^{a}$ & $15 \cdot 3^{a}$ & $14 \cdot 6^{a, b}$ & $13 \cdot 3^{b}$ & 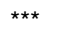 & $14 \cdot 0^{\mathrm{a}}$ & $12 \cdot 8^{\mathrm{a}, \mathrm{b}}$ & $12 \cdot 2^{\mathrm{a}, \mathrm{b}}$ & $11 \cdot 5^{\mathrm{b}}$ & * \\
\hline$\%$ Energy from fat & $33 \cdot 4$ & $34 \cdot 7$ & $33 \cdot 8$ & 33.5 & NS & $36 \cdot 4$ & $36 \cdot 9$ & $42 \cdot 3$ & $46 \cdot 3$ & NS \\
\hline$\%$ Energy from saturated fat & 14.5 & $15 \cdot 1$ & 14.5 & 14.5 & NS & 14.5 & 14.5 & 14.4 & $14 \cdot 2$ & ** \\
\hline Fibre/energy (g/10 MJ) & $14 \cdot 9^{\mathrm{a}}$ & $16 \cdot 8^{\mathrm{b}}$ & $18 \cdot 4^{\mathrm{C}}$ & $19 \cdot 6^{\mathrm{C}}$ & 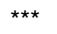 & $16 \cdot 4^{\mathrm{a}}$ & $16 \cdot 9^{\mathrm{a}}$ & $18 \cdot 6^{\mathrm{b}}$ & $22 \cdot 0^{\mathrm{C}}$ & $\star * \star$ \\
\hline $\mathrm{Na} /$ energy (mg/10 MJ) & 3042 & 3027 & 3103 & 3026 & NS & $2938^{a}$ & $3178^{b}$ & $3086^{a, b}$ & $3020^{a, b}$ & * \\
\hline Fe/energy (mg/10 MJ) & $12 \cdot 1^{a, b}$ & $12 \cdot 1^{a}$ & $13 \cdot 5^{\mathrm{b}}$ & $15 \cdot 1^{c}$ & 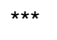 & $15 \cdot 5$ & $15 \cdot 8$ & $14 \cdot 3$ & $17 \cdot 1$ & NS \\
\hline $\mathrm{Ca} /$ energy (mg/10 MJ) & 1216 & 1219 & 1239 & 1294 & NS & 1010 & $996 \cdot 5$ & 1084 & 1162 & NS \\
\hline Vitamin E/energy (mg/10 MJ) & $9 \cdot 0$ & $8 \cdot 6$ & $9 \cdot 4$ & $9 \cdot 8$ & NS & $9 \cdot 8$ & 9.4 & $10 \cdot 1$ & 11.9 & NS \\
\hline K/energy (mg/10 MJ) & $3025^{a}$ & $3110^{a, b}$ & $3080^{a}$ & $3238^{b}$ & ** & $3153^{a}$ & $3157^{a, b}$ & $3219^{b}$ & $3275^{a, b}$ & * \\
\hline P/energy (mg/10 MJ) & $1347^{\mathrm{a}}$ & $1416^{a, b}$ & $1443^{b}$ & $1550^{C}$ & $\star \star \star \star ~$ & $1360^{\mathrm{a}, \mathrm{b}}$ & $1354^{\mathrm{a}}$ & $1452^{\mathrm{b}}$ & $1567^{\mathrm{C}}$ & *** \\
\hline Mg/energy $(\mathrm{mg} / 10 \mathrm{MJ})$ & $247 \cdot 5^{\mathrm{a}}$ & $260 \cdot 0^{\mathrm{a}}$ & $271 \cdot 3^{\mathrm{b}}$ & $305 \cdot 5^{\mathrm{c}}$ & 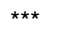 & $252 \cdot 9^{a}$ & $257 \cdot 9^{\mathrm{a}}$ & $278 \cdot 4^{\mathrm{b}}$ & $316 \cdot 7^{\mathrm{C}}$ & *** \\
\hline Thiamin/energy (mg/10 MJ) & $2 \cdot 2$ & $2 \cdot 0$ & $2 \cdot 1$ & $2 \cdot 6$ & NS & 1.9 & $2 \cdot 4$ & $2 \cdot 7$ & $3 \cdot 2$ & NS \\
\hline Riboflavin/energy (mg/10 MJ) & $2 \cdot 4^{\mathrm{a}, \mathrm{b}}$ & $2 \cdot 4^{\mathrm{a}}$ & $2 \cdot 5^{a, b}$ & $3 \cdot 1^{\mathrm{b}}$ & * & $2 \cdot 1^{\mathrm{a}}$ & $2 \cdot 3^{\mathrm{a}}$ & $3 \cdot 0^{a, b}$ & $3.9^{\mathrm{b}}$ & * \\
\hline Niacin/energy (mg/10 MJ) & $25 \cdot 3^{a, b}$ & $22 \cdot 7^{\mathrm{a}}$ & $24 \cdot 9^{\mathrm{a}, \mathrm{b}}$ & $27 \cdot 0^{\mathrm{b}}$ & $* * *$ & $23 \cdot 1^{a}$ & $25 \cdot 7^{\mathrm{a}, \mathrm{b}}$ & $28 \cdot 2^{b, c}$ & $29 \cdot 8^{\mathrm{C}}$ & * \\
\hline Vitamin $B_{6}$ /energy $(\mathrm{mg} / 10 \mathrm{MJ})$ & $3 \cdot 0$ & $2 \cdot 7$ & $2 \cdot 8$ & $3 \cdot 3$ & NS & $2 \cdot 9$ & $3 \cdot 1$ & 3.5 & $3 \cdot 8$ & NS \\
\hline Vitamin $B_{12} /$ energy $(\mu \mathrm{g} / 10 \mathrm{MJ})$ & $5 \cdot 6$ & $6 \cdot 0$ & $6 \cdot 2$ & $6 \cdot 9$ & NS & $5 \cdot 2$ & $5 \cdot 5$ & $6 \cdot 0$ & $6 \cdot 9$ & NS \\
\hline Vitamin D/energy ( $\mu \mathrm{g} / 10 \mathrm{MJ})$ & $2 \cdot 8$ & $3 \cdot 0$ & 3.4 & 3.5 & NS & $2 \cdot 2$ & $3 \cdot 1$ & 3.4 & 3.5 & NS \\
\hline
\end{tabular}

a,b,c Mean values with unlike superscript letters were significantly different between non-consumers and tertiles of whole grain intakes for mean intakes of whole grain food groups (adjusted for sex) (ANCOVA, Bonferroni post hoc test).

Mean values were significantly different: ${ }^{\star} P<0.05 ;{ }^{*} P<0.01 ;{ }^{* \star \star} P<0.001$; NS $(P \geq 0.05)$. 
awareness, suggests a potential to further improve compliance to recommendations in future years.

There are a number of strengths and limitations associated with the present study that deserve mentioning. First, a definite strength of this analysis was the thorough data collection methodology that was followed, providing very detailed information on whole grain intakes. Previous similar studies have used $24 \mathrm{~h}_{\text {recall }}^{(24)}, \mathrm{FFQ}^{(1,56)}$ and $3 \mathrm{~d}$ weighed food diaries ${ }^{(14)}$. The present study, however, used $7 \mathrm{~d}$ weighed (children) and semi-weighed (teenagers) food diaries, with continuous involvement of the research team (four visits per subject). In addition, over $46 \%$ of whole grain data were collected at the brand level.

In terms of limitations, data received from manufacturers and food labels must be accepted with caution. Further investigation of whole grain pasta consumed in the present study labelled as $100 \%$ durum whole wheat semolina was found to contain just $88 \%$ whole grain content by alkylresorcinol analysis. A second limitation of the present study is the possibility of under-reporting, which would result in the underestimation of whole grain intakes. In addition, despite best efforts to encourage respondents to maintain usual eating practices, the burden of completing $7 \mathrm{~d}$ dietary records is acknowledged. Furthermore, the lack of involvement from very low socioeconomic groups and those with poor or self-conscious health lifestyles must also be taken into account; these problems being not uncommon in large food-consumption surveys.

In conclusion, despite high consumer rates of whole grain, the percentage of Irish children and teenagers meeting whole grain recommendations advised by the United States Department of Agriculture ${ }^{(16)}$ is poor. RTEBC were the greatest provider of whole grain, with wheat being the primary source. In the present study, whole grain intake was associated with a more nutrient-dense diet. To further improve whole grain intakes in Irish children and teenagers, a combination of effective nutritional education programmes and increased product availability and variety are required.

\section{Acknowledgements}

The present analysis was supported by Cereal Partners Worldwide. A. P. N., B. A. Mc. N. and M. J. G. received the research funding; N. F. C. D. conducted the analysis for the paper and has no conflict of interest; the analysis was supervised by B. A. Mc. N. and A. P. N.; F. T. and H. S. are employed by Cereal Partners Worldwide and helped in designing the study and observed the analysis closely over the course of the study; M. J. G. was the principal investigator of the NCFS and the NTFS. All authors reviewed the manuscript. We acknowledge the assistance of Tim E. Grant (statistician at CStar, http://www.CStar.ie) for his advice on statistical components of the study.

\section{References}

1. McKeown NM, Meigs J, Liu S, et al. (2002) Whole-grain intake is favourably associated with metabolic risk factors for type 2 diabetes and cardiovascular disease in the Framingham Offspring Study. Am J Clin Nutr 76, 390-398.
2. Newby P, Maras J, Bakun P, et al. (2007) Intake of whole grains, refined grains, and cereal fiber measured with 7-d diet records and associations with risk factors for chronic disease. Am J Clin Nutr 86, 1745-1753.

3. Jensen MK, Koh-Banerjee P, Franz M, et al. (2006) Whole grains, bran, and germ in relation to homocysteine and markers of glycemic control, lipids, and inflammation. Am J Clin Nutr 83, 275-283.

4. Slavin J (2004) Whole grains and human health. Nutr Res Rev 17, 99-110.

5. Harland JI \& Garton LE (2007) Whole-grain intake as a marker of healthy body weight and adiposity. Public Health Nutr 11, 554-563.

6. Pereira MA, Jacobs D Jr, Pins JJ, et al. (2002) Effect of whole grains on insulin sensitivity in overweight hyperinsulinemic adults. Am J Clin Nutr 75, 848-855.

7. Tighe P, Duthie G, Vaughan N, et al. (2010) Effect of increased consumption of whole-grain foods on blood pressure and other cardiovascular risk markers in healthy middle-aged persons: a randomized controlled trial. $\mathrm{Am} \mathrm{J}$ Clin Nutr 92, 733-740.

8. Giacco R, Clemente G, Cipriano D, et al. (2010) Effects of the regular consumption of wholemeal wheat foods on cardiovascular risk factors in healthy people. Nutr Metab Cardiovasc Dis 20, 186-194.

9. Gold K, Wong N, Tong A, et al. (1991) Serum apolipoprotein and lipid profile effects of an oat-bran-supplemented, lowfat diet in children with elevated serum cholesterol. Ann $N$ $Y$ Acad Sci 623, 429-431.

10. Steffen LM, Jacobs D Jr, Murtaugh M, et al. (2003) Whole grain intake is associated with lower body mass and greater insulin sensitivity among adolescents. Am J Epidemiol 158, $243-250$.

11. American Association of Cereal Chemists (2005) Definition/ Reports. http://www.aaccnet.org/definitions/wholegrain.asp (accessed September 2011).

12. Richardson DP (2003) Wholegrain health claims in Europe. Proc Nutr Soc 62, 161-169.

13. Whole Grains Council. Governemnt Guidance. http://www. wholegrainscouncil.org/whole-grain-stamp/governemntguidance (accessed October 2011).

14. Alexy U, Zorn C \& Kersting M (2010) Whole grain in children's diet: intake, food sources and trends. Eur J Clin Nutr 64, 745-751.

15. Thane CW, Jones AR, Stephen AM, et al. (2005) Whole-grain intake of British young people aged 4-18 years. Br J Nutr 94, $825-831$.

16. U.S. Department of Agriculture \& U.S. Department of Health and Human Services (2010) Dietary Guidelines for Americans 2010, 7th ed. Washington, DC: U.S. Government Printing Office.

17. Griffiths T (2007) Towards an Australian 'daily target intake' for whole grains. Food Australia 59, 12.

18. Mejborn H, Biltoft-Jensen A, Trolle E, et al. (2008) Wholegrain - Definition and Scientific Background for Recommendations of Wholegrain Intake in Denmark. Søborg. Fødevareinstituttet, Danmarks Tekniske Universitet.

19. van der Kamp JW (2010) Wholegrain definition, recommended intake and results of Healthgrain. 2nd World Congress of Public Health Nutrition, Porto, Portugal.

20. NHS (2011) The eatwell plate. www.nhs.uk/Livewell/Goodfood/Pages/eatwell-plate.aspx

21. German Nutrition Society (2005) 10 guidelines of the German Nutrition Society (DGE) for a wholesome diet. http://www.dge.de/modules (accessed October 2011). 
22. O'Neil CE, Zanovec M, Cho SS, et al. (2010) Whole grain and fiber consumption are associated with lower body weight measures in US adults: National Health and Nutrition Examination Survey. Nutr Res 30, 815-822.

23. Thane CW, Jones AR, Stephen AM, et al. (2007) Comparative whole-grain intake of British adults in 1986-7 and 2000-1. Br J Nutr 97, 987-992.

24. Zanovec M, O'Neil CE, Cho SS, et al. (2010) Relationship between whole grain and fiber consumption and body weight measures among 6- to 18-year-olds. J Pediatr 157, 578-583.

25. Deschamps V, Malon A, Salanave B, et al. (2009) Compliance with French diet recommenations in 3-17-year-old children The French nutrition and health survey (ENNS, 2006-2007). In 19th International Congress of Nutrition, Thailand.

26. Central Statistics Office (2003) Census 2002 Principal Demographic Results. Dublin: The Stationery Office.

27. Holland B, Welch A, Unwin I, et al. (1995) McCance E Widdowson's The Composition of Foods, 5th ed. London: HMSO.

28. Agency FS (2002) McCance and Widdowson's The Composition of Foods, 6th summary ed. Cambridge: Royal Society of Chemistry.

29. Holland B, Unwin ID \& Buss DH (1992) Fruits and Nuts. First Supplement to McCance \& Widdowson's The Composition of Foods, 5th ed. London: HMSO.

30. Chan W, Brown J \& Buss D (1994) Miscellaneous Foods. Fourth Supplement to McCance \& Widdowson's The Composition of Foods, 5th ed. London: HMSO.

31. Chan W, Brown J, Church S, et al. (1996) Meat Products and Dishes. Sixth Supplement to McCance \& Widdowson's The Composition of Foods, 5th ed. London: HMSO.

32. Chan W, Brown J, Lee S, et al. (1995) Meat, Poultry and Game Fifth Supplement to McCance \& Widdowson's The Composition of Foods, 5th ed. London: HMSO.

33. Holland B, Brown J \& Buss D (1993) Fish and Fish Products Third Supplement to McCance \& Widdowson's The Composition of Foods, 5th ed. London: HMSO.

34. Holland B, Unwin I \& Buss D (1991) Vegetables, Herbs and Spices. Fifth Supplement to McCance \& Widdowson's The Composition of Foods, 4 ed. London: HMSO.

35. Holland B, Unwin I \& Buss D (1989) Milk Products and Eggs. Fourth Supplement to McCance \& Widdowson's The Composition of Foods, 4th ed. London: HMSO.

36. Holland B, Unwin I \& Buss D (1988) Cereal and Cereal Products. Third Supplement to McCance \& Widdowson's The Composition of Foods, 4th ed. London: HMSO.

37. Holland B, Welch A \& Buss D (1996) Vegetable Dishes Second Supplement to McCance \& Widdowson's The Composition of Foods, 5th ed. London: HMSO.

38. Joyce T, McCarthy SN \& Gibney MJ (2008) Relationship between energy from added sugars and frequency of added sugars intake in Irish children, teenagers and adults. BrJ Nutr 99, 1117-1126.

39. Gilsenan M, Lambe J \& Gibney M (2002) Irish National Food Ingredient Database: application for assessing patterns of additive usage in foods. Food Addit Contam 19, 1105-1115.
40. Gidding SS, Dennison BA, Birch LL, et al. (2005) Dietary recommendations for children and adolescents: a guide for practitioners: consensus statement from the American Heart Association. Circulation 112, 2061-2075.

41. Wearne S \& Day M (1999) Clues for the development of food-based dietary guidelines: how are dietary guidelines being achieved by UK consumers? Br J Nutr 81, S119-S126.

42. Mellen PB, Walsh TF \& Herrington DM (2008) Whole grain intake and cardiovasuclar disease: a meta-analysis. Nutr Metab Cardiovasc Dis 18, 283-290.

43. Sun Q, Spiegelman D, van Dam RM, et al. (2010) White rice, brown rice, and risk of type 2 diabetes in US men and women. Arch Intern Med 170, 961-969.

44. Aune D, Chan DSM, Lau R, et al. (2011) Dietary fibre, whole grains, and risk of colorectal cancer: systematic review and dose-response meta-analysis of prospective studies. BMJ 343, d6617.

45. Masters RC, Liese AD, Haffner SM, et al. (2010) Whole and refined grain intakes are related to inflammatory protein concentrations in human plasma. J Nutr 140, 587-594.

46. Flint AJ, Hu FB, Glynn RJ, et al. (2009) Whole grains and incident hypertension in men. Am J Clin Nutr 90, 493-498.

47. Deasy C, Walton J, Hannon EM, et al. (2006) Dietary fibre and NSP intake in Irish children aged 5-12 years. Proc Nutr Soc 65, 41A.

48. Bannon S, Walton J, Hannon EM, et al. (2009) Dietary fibre and NSP intake in Irish teenagers aged 13-17 years. Proc Nutr Soc 67, E272.

49. Williams CL, Bollella M \& Wynder EL (1995) A new recommendation for dietary fiber in childhood. Pediatrics 96, 985-988.

50. Harnack L, Walters S \& Jacobs D Jr (2003) Dietary intakes and food sources of whole grains among US children and adolescents: data from the 1994-1996 continuing survey of food intakes by individuals. J Am Diet Assoc 103, 1015-1019.

51. Hannon EM \& Flynn A (2007) Contribution of ready to eat breakfast cereals to nutrient intakes in Irish children aged 5-12 years. Proc Nutr Soc 66, 43A.

52. Walsh E, Hannon EM, Walton J, et al. (2011) Contribution of ready to eat breakfast cereals to nutrient intakes in Irish teenagers aged 13-17 years. In 11th FENS European Nutrition Conference, 26-29 October, Madrid.

53. Lang R, Thane CW, Caroline B-S, et al. (2002) Consumption of whole grain foods by British adults: findings from further analysis of two national dietary surveys. Public Health Nutr 6, 479-484.

54. Cleveland LE, Moshfegh AJ, Albertson AM, et al. (2000) Dietary intake of whole grains. J Am Coll Nutr 19, 331S-338S.

55. Mintel Global New Products Database (2011) www.mintel.com (accessed March 2012)

56. Jacobs DJ, Meyer K, Kushi L, et al. (1998) Whole-grain intake may reduce the risk of ischemic heart disease death in postmenopausal women: the Iowa Women's Health Study. Am J Clin Nutr 68, 248-257. 